\title{
El género Galeandra (Orchidaceae) en Argentina
}

\author{
The genus Galeandra (Orchidaceae) in Argentina
}

Christian A. Zanotti ${ }^{1,3}$, Juan C. Ospina ${ }^{1} \&$ Silvana H.N. Monteiro $^{2}$

\begin{abstract}
Resumen
Galeandra (Orchidaceae) comprende alrededor de 18 especies de hierbas epífitas y terrestres de distribución neotropical, las cuales son reconocidas por presentar las flores con el labelo en forma de embudo y espolonado en la base. Cuatro especies de Galeandra fueran citadas para la flora Argentina en previos trabajos taxonómicos: $G$. beyrichii, G. graminoides, G. hysterantha y G. styllomisantha. El objetivo de esta contribución fue realizar el estudio taxonómico de Galeandra en Argentina. Se reconocen a G. beyrichii y G. xerophila para el territorio argentino, esta última se cita por primera vez. Galeandra graminoides y G. stylomisantha, se consideran como citas dudosas para la flora Argentina. El tratamiento incluye una clave de identificación, descripciones, fotografías de campo, observaciones, distribución y hábitat para cada especie.
\end{abstract}

Palabras clave: Catasetinae, flora del Cono Sur, taxonomía.

\begin{abstract}
Galeandra (Orchidaceae) comprises about 18 species of epiphytic and terrestrial neotropical herbs. The genus is recognized by its flowers with funnel-shaped lip and spurred at the base. Four species of Galeandra have been recognized for the Argentinean flora in previous taxonomics studies: G. beyrichii, G. graminoides, G. hysterantha and G. styllomysantha. The aim of this contribution was to do a taxonomic treatment of Galeandra for Argentina. We recognize to G. beyrichii and G. xerophila, the last one is a new record for the argentinean flora. Galeandra graminoides and G. stylomisantha, are considered a doubtful report. The treatment includes an identification key, descriptions, geographic distributions data and habitat, field photographs, observations and comments on each species.

Key words: Catasetinae, Cono Sur flora, taxonomy.
\end{abstract}

\section{Introducción}

Galeandra Lindl. es un género de la familia Orchidaceae que comprende alrededor de 18 especies de hierbas epífitas y terrestres de distribución neotropical, las cuales, se distribuyen desde el sur de Florida hasta el norte de la Argentina, siendo Brasil el país con mayor riqueza específica (Monteiro et al. 2010). Este género se caracteriza principalmente por presentar el labelo en forma de embudo y espolonado en la base (Bochorny et al. 2015), y se ha demostrado, mediante estudios moleculares, que Galeandra es monofilético (Monteiro et al. 2010).

Los caracteres morfológicos más usados para separar las especies de este género son: la forma del pseudobulbo, la morfología del labelo, la forma de la columna y la forma de vida (Monteiro et al. 2010).
Sin embargo, la sistemática y la taxonomía de esta entidad, son controvertidas, debido a la dificultad del reconocimiento de estos caracteres en los ejemplares de herbario y a la falta de una clave taxonómica integral para las especies.

Los trabajos taxonómicos en donde han sido tratadas las especies de Galeandra para la Argentina, fueron realizados por Hauman (1921), quien reconoció a $G$. beyrichii Rchb. f. para la provincia de Salta. Posteriormente, Williams (1939) citó a G. graminoides Barb. Rodr. para las provincias de Salta y Tucumán, sin considerar la especie citada por Hauman (1921); ya que el autor menciona que no logró observar la colección de referencia para dicho taxón. Por otra parte, G. stylomisantha (Vell.) Hoehne fue citada por primera vez para las

\footnotetext{
Instituto de Botánica Darwinion (ANCEFN-CONICET), Labardén 200, Casilla de Correo 22, B1642HYD San Isidro, Buenos Aires, Argentina.

${ }^{2}$ Instituto de Pesquisas Jardim Botânico do Rio de Janeiro, Herbário, R. Pacheco Leão 915, Horto, 22460-030, Rio de Janeiro, RJ, Brasil.

${ }^{3}$ Autor para la correspondencia: czanotti@darwin.edu.ar
} 
provincias de Corrientes y Misiones por Correa (1995). Finalmente, Correa (1996) y Schinini (2008) reconocieron cuatro especies de este género para la flora Argentina: $G$. beyrichii, $G$. graminoides, $G$. hysterantha Barb. Rodr. y G. stylomisantha. Sin embargo, la identidad de las especies del género Galeandra citadas para la Argentina es controversial, debido a que el material de referencia citado en estos trabajos está basado en ejemplares erróneamente determinados.

El objetivo de esta contribución es aclarar la taxonomía del género Galeandra para la flora Argentina, a través de una clave de identificación, descripciones, datos de distribución geográfica, fotografías de campo y comentarios para cada especie.

\section{Materiales y Métodos}

Se examinaron ejemplares depositados en los herbarios AMES, BAB, CTES, LIL, MU, SI (Thiers, permanentemente actualizado) y observaciones sobre el hábitat para $G$. xerophila en el campo (octubre 2013). Las descripciones morfológicas siguen la terminología de Stearn (2004) y Monteiro (2007).

Se consultaron los protólogos e imágenes digitales de los ejemplares tipo disponibles en JSTOR (<http://plants.jstor.org $>$ ) para cada una de las especies. La distribución sigue la división fitogeográfica propuesta por Cabrera \& Willink (1973), y se incluyó la información proporcionada en las exsiccatas analizadas.

\section{Resultados y Discusión}

A partir del estudio de las 17 exsiccatas correspondientes al género Galeandra, se reconocieron dos especies para la flora Argentina: G. beyrichii y G. xerophila, provenientes de las provincias fitogeográficas Paranaense y de las Yungas. Se cita por primera vez a $G$. xerophila y se consideran como citas dudosas a G. graminoides y G. stylomisantha para la flora Argentina.

Galeandra Lindl., Ill. Orch. Pl. tab. 8. 1832. Corydandra Rchb., nom. illeg. Deut. Bot. Herb.Buch 53. 1841.

Hierbas terrestres o epífitas. Pseudobulbos subterráneos, ovoides, recubiertos por vainas foliares imbricadas y persistentes. Hojas lineares a oblongo lanceoladas (raramente ausentes), dísticas, coriáceas, glabras. Inflorescencias racimosas, erectas, con 3 a 16 flores; pedúnculo cilíndrico y recubierto por una o más brácteas triangulares-lanceoladas, imbricadas y escariosas. Flores con el pedicelo recto, con una bráctea en la base semejante a las del pedúnculo; sépalos y pétalos oblongo-lanceolados, libres, membranáceos, rectos a reflexos; sépalo dorsal ligeramente más largo que los laterales; labelo infundibuliforme, 3-lobado (naturalmente), rómbico o rómbico-ovado (cuando se encuentra extendido), membranáceo, pubescente, margen liso a crenulado, ápice acuminado a emarginado; disco compuesto por 2-4 carenas paralelas, pubérulas; espolón cónico o filiforme con el ápice agudo a obtuso; columna apiculada, ligeramente curvada, glabra o pubérula, cavidad del estigma con alas laterales; antera 2-locular, suborbicular, con el ápice obtuso; polínias 2, ovoides, libres. Fruto cápsula, oblonga, 3-carpelar, dehiscente, seco; semillas numerosas.

\section{Clave para las especies de Galeandra (Orchidaceae) presentes en Argentina:}

1. Plantas áfilas durante la etapa reproductiva. Sépalos verde claro. Vainas foliares escariosas. Labelo con ápice retuso y espolón cónico con el ápice obtuso. 1. Galeandra beyrichii

1'. Plantas con hojas durante la etapa vegetativa y reproductiva. Sépalos castaños-verdosos. Vaina foliares coriáceas. Labelo con ápice trilobulado y espolón filiforme con ápice agudo

2. Galeandra xerophila

1. Galeandra beyrichii Rchb. f., Linnaea 22: 854. $1849[1850]$.

Galeandra hysterantha Barb. Rodr., Gen. Sp. Orchid. 1: 86, 1877.

Galeandra viridis Barb.Rodr., Rev. De Engen.: 143. 1881.

Galeandra coxinnensis Hoehne, Relat. Commiss.
Linhas Telegr. Estratég. Mato Grosso Amazonas annexo 5, Bot. 4: 15 (t. 70). 1912.

Galeandra fiebrigii Schltr., Repert. Spec. Nov. Regni Veg. Beih. 10: 47. $1922 . \quad$ Fig. 2c-d

Plantas terrestres de 20-70 $\mathrm{cm}$ de largo. Pseudobulbos de 1-2,5 × 1-2 cm, ovoides. Hojas ausentes durante la etapa reprodutiva; vainas 
foliares de 2-10 cm de largo, escariosas e imbricadas. Inflorescencias en racimos, erectas, con 6-16 flores; pedúnculo de $18-40 \mathrm{~cm}$ de largo, brácteas del pedúnculo de $3-10 \mathrm{~cm}$ de largo, lanceoladas; raquis de la inflorescencia de 7-30 cm de largo, bráctea floral de $1-4 \mathrm{~cm}$ de largo. Flores de 1,5-3,5 cm de largo, sépalos y pétalos verde claro; sépalo dorsal $2-3,5 \times$ $0,4-0,6 \mathrm{~cm}$; sépalos laterales $2-3 \times 0,4-0,7$ $\mathrm{cm}$; pétalos $1-3 \times 0,4-0,7 \mathrm{~cm}$; labelo $1,5-2,5 \times$ 2-3,5 cm, exteriormente blanco-verdoso y con las nervaduras marcadas internamente blancoverdoso y densamente pubescente, bordes con estrías púrpuras, margen crenada, ciliolada, ápice retuso, disco 4-carinado, carenas verdosas, vilosas progresivamente hacia el ápice, espolón de 5-6 $\mathrm{mm}$ de largo, cónico con ápice obtuso, nervaduras marcadas, internamente pubescente; columna $0,8-1 \times 0,3-0,5 \mathrm{~cm}$, pubérula. Fruto $2-3 \times 0,5-1 \mathrm{~cm}$.

Material examinado: Corrientes, Depto. Ituzaingó, $15 \mathrm{~km}$ E de Ruta Nacional 12, camino a San Carlos, 11.II.1971, fl., A. Krapovickas et al. 17933 (CTES); Jujuy, Depto. Ledesma, Parque Nacional Calilegua, confluencia Arroyo Tres Cruces y Negrito, 26.VIII.1997, fl., A.E. Johnson \& P. Giorgis 796 (SI); Sendero Tataupa, 27.I.1999, fl., A.E. Johnson 816 (SI); Sendero Cascada, 28.I.1999, fl., A.E. Johnson 817 (SI); Sendero La Junta, 5.II.1999, fl., A.E. Johnson 822 (MU, SI); Misiones, Depto. Bernardo de Irigoyen, 5.I.1968, fl. y fr., A. Krapovickas \& C.L. Cristóbal 13708 (CTES); Depto. General Manuel Belgrano, Reserva Estricta

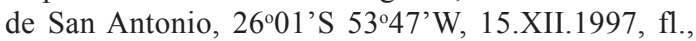
M.E. Múlgura et al. 1878 (SI); Depto. Iguazú, Paraje Aguaray, Lote P.A.P.S.A., cerca del pantano "La Alpargata", 20.XII.2003, f1., M.M. Sosa \& H.A. Keller 112 (CTES); Depto. Oberá, Camino al Salto Krysiuk,

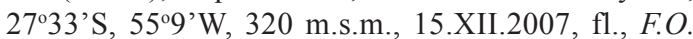
Zuloaga et al. 9866 (SI); Salta, Depto. Anta, Finca "El Rey", Agua Negra, 1000 m.s.m., 2.II.1954, fl. y fr., $T$. Meyer 18374 (LIL).

Galeandra beyrichii se diferencia de las demás especies del género por carecer de hojas (al menos durante la floración). Se encuentra desde el sur de Florida, México, América Central, Venezuela, Colombia, Perú, Bolivia, Brasil, Paraguay, Uruguay, noroeste y noreste de la Argentina (Monteiro et al. 2009; Bochorny et al. 2015). En la Argentina crece en la provincia fitogeográfica Paranaense, en los distritos de las Selvas Mixtas y de los Campos; y en el sotobosque de la Selva Pedemontana de la provincia fitogeográfica de Las Yungas. Habita sobre suelos arcillosos compactos y húmedos, hasta los 1000 m s.m (Fig. 1).
Galeandra hysterantha fue citada por primera vez para la flora argentina por Correa (1996) y Schinini et al. (2008) para las provincias de Corrientes y Misiones, sobre la base de la colección Krapovickas et al. 17933 (CTES), el cual coincide con las características descriptas para G. beyrichii.

2. Galeandra xerophila Hoehne, Comm. Lin. Telegr., Bot. 5: 45, t. 92.1915.

Fig. 2a-b

Plantas terrestres de $20-45 \mathrm{~cm}$ de largo, con pseudobulbos $5 \times 2 \mathrm{~cm}$, ovoides . Hojas $8-30 \times$ 0,5-1,5 cm, oblongo-lanceoladas; vainas foliares coriáceas 3,5-6(-8) $\mathrm{cm}$ de largo e imbricadas. Inflorescencias en racimos, erectas, con 3-12 flores; pedúnculo de 4-10 $\mathrm{cm}$ de largo, brácteas del pedúnculo de 1,5-2 cm de largo, lanceoladas; raquis de la inflorescencia de $5-15 \mathrm{~cm}$ de largo, bráctea floral de $4-8 \mathrm{~mm}$ de largo. Flores de 1,5-3 cm de largo, sépalos y pétalos verdososcastaños; sépalo dorsal de $1 \times 0,3 \mathrm{~cm}$; sépalos laterales de $1,1 \times 0,2 \mathrm{~cm}$; pétalos de $0,9 \times 0,3$ $\mathrm{cm}$; labelo de $2-3 \times 1,5 \mathrm{~cm}$, exteriormente e internamente blanco-verdoso y con las nervaduras castañas, densamente pubescentes, margen crenada, ciliolada, ápice 3-lobulado, lóbulo del medio obtuso y los laterales redondeados, disco 4-carinado, carenas púrpureas, vilosas, espolón de 5-10 $\mathrm{mm}$ de largo, verdoso, filiforme, ápice agudo, nervaduras marcadas, internamente pubescente; columna $0,8 \times 0,2 \mathrm{~cm}$, pubérula. Fruto no visto.

Material examinado: Salta, Depto. Orán, Sabana al oeste de San Ramón de la Nueva Orán, $23^{\circ} 10^{\prime} 43^{\prime}$ 'W 64²0'26”'S, 366 m.s.m., 29.X.2013, fl., A. Grau \&

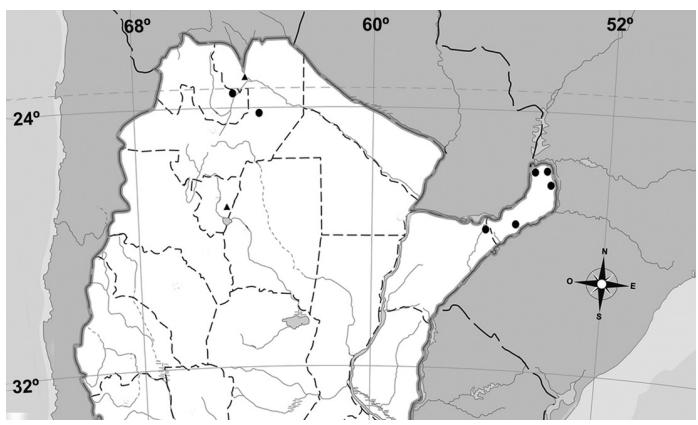

Figura 1 - Mapa de distribución geográfica de Galeandra en la Argentina: G.beyrichii (círculos) y G. xerophilla (triángulos).

Figure 1 - Geographic distribution map of Galeandra in Argentina G.beyrichii (circles) y G. xerophilla (triangles). 

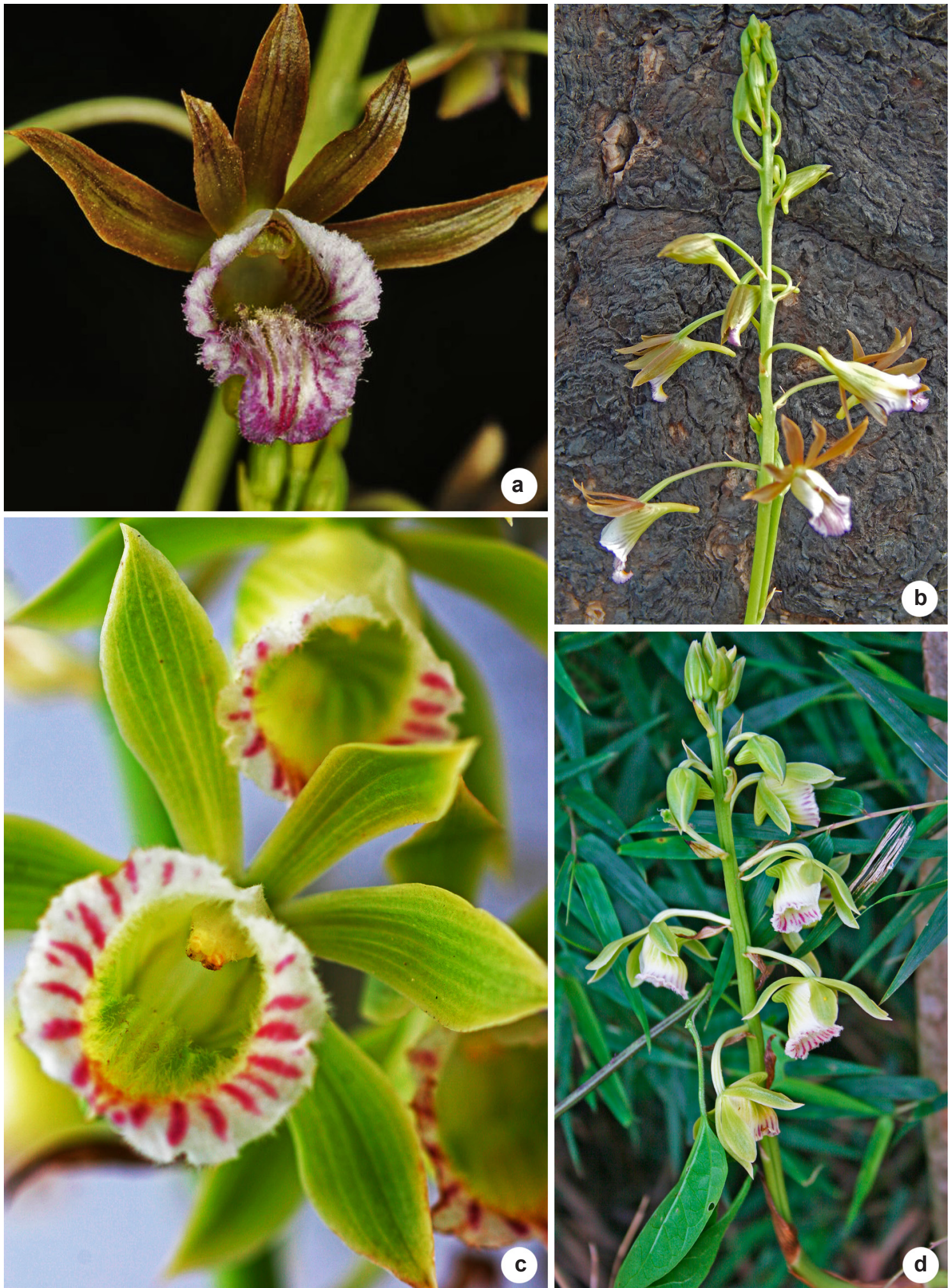

Figura 2 - a-b. Galeandra xerophilla - a. flor; b. inflorescencia. c-d. Galeandra beyrichii-c. flor; d. inflorescencia (Fotos: a. C. Zanotti; b. A. Grau; c,d. F.O. Zuloaga).

Figure 2 - a-b. Galeandra xerophilla - a. flower; b. inflorescence. c-d. Galeandra beyrichii - c. flower; d. inflorescence (Photos: a. C. Zanotti; b. A. Grau; c,d. F.O. Zuloaga). 
C.A. Zanotti 12 (LIL, SI); Ruta 50, $2 \mathrm{~km}$ al W de San Ramón de la Nueva Orán, 360 m.s.m., 4.XII.2005, fl., M.M. Arbo et al. 8984 (CTES); Abra Grande, 650 m.s.m., XI.1907, fl., S. Venturi 5756 (AMES, LIL, SI); Tucumán, Depto. Cruz Alta, Campo Alegre, Km 754 F.C.C.N, 29.X.1922, fl., R. Schreiter (AMES-49194, LIL); 400 m.s.m., 18.XI.1923, fl., R. Schreiter 1883 (AMES, LIL); Estación Aráoz (F.C.C.N.), 450 m.s.m., 21.XI.1921, fl., R. Schreiter 4029 (AMES, LIL); 416 m.s.m., 27.XI.1921, fl., S. Venturi 1546 (LIL, SI).

Galeandra xerophila se distribuye en Brasil y en el noroeste de la Argentina (Monteiro 2007). Crece en el distrito de las Selvas de Transición de la provincia fitogeográfica de Las Yungas, principalmente en la sabana de la selva pedemontana, entre 350-400 m. (Fig. 1), la cual fue encontrada en ecosistemas donde se producen habitualmente incendios naturales (Grau \& Zanotti 12 y Arbo et al. 8984).

Citas dudosas para la flora argentina Galeandra graminoides Barb.Rodr., Gen. Sp. Orchid. 1: 88. 1877.

Galeandra graminoides fue citada por Williams (1939) para la flora Argentina para las provincias de Salta y Tucumán. En este trabajo, se confirmó que los ejemplares determinados bajo esta especie, citados por Williams (1939), corresponden a G. xerophila. Posteriormente, G. graminoides fue citada para las provincias de Formosa y Santiago del Estero por Correa (1996) y Schinini et al. (2008). Sin embargo, no se encontraron ejemplares que avalen la presencia de ninguna de las especies de Galeandra citadas en dichas provincias.

Galeandra styllomisantha (Vell.) Hoehne, Arq. Bot. estado São Paulo 2: 146. 1952. Orchis styllomisantha Vell., Fl. Flumin. 9: t. 46. 1831.

Galeandra juncea Lindl., Sert. Orchid. sub t. 37. 1840.

Galeandra styllomysantha se caracteriza principalmente por presentar el labelo con el margen crenulado y el ápice emarginado (Monteiro et al. 2009; Bochorny et al. 2015). Crece en Panamá, Venezuela, Colombia, Bolivia, Perú, Guayanas, Surinam, Guayanas Francesas hasta el Brasil, siendo el registro más austral en el estado de Paraná, en donde se halle probablemente extinta (Bochorny et al. 2015).

Galeandra styllomysantha fue citada para la flora argentina, en las provincias de Misiones y Corrientes por Correa (1995) sobre la base del ejemplar Correa et al. 8533 (BAB), esta colección fue posteriormente citada por Correa (1996) y
Schinini et al. (2008). Sin embargo, este ejemplar no fue localizado en el herbario correspondiente y no se observaron otras colecciones que permitan confirmar la presencia de este taxón para la Argentina. Por lo tanto, consideramos a $G$. styllomysantha como especie dudosa para la flora Argentina.

\section{Agradecimientos}

A Alfredo Grau y Alejandro Brown por permitirnos realizar un viaje de colección donde se encontró a G. xerophylla. A A. Grau por la foto de la inflorescencia de G. xerophilla. A los dos revisores anónimos y al editor (Dr. Luiz Menini) por las revisiones y sugerencias que ayudaron a mejorar este manuscrito.

\section{Referencias}

Bochorny, T.; Monteiro, S.H.N. \& Smidt, E.C. 2015. O gênero Galeandra (Orchidaceae: Catasetinae) no estado do Paraná, Brasil. Rodriguésia 66: 221-227.

Cabrera, A.L. \& Willink, A.W. 1973. Biogeografía de América Latina. Serie de Biología OEA. Monografía 13: 1-117.

Correa, M.N. 1995. Novedades en Orchidaceae de Argentina. Hickenia 2: 165-175.

Correa, M.N. 1996. Orchidaceae. In: Zuloaga, F.O. \& Morrone, O. (eds.). Catálogo de las plantas vasculares de la República Argentina I (Pteridophyta, Gymnospermae y Angiospermae (Monocotyledoneae). Monographs in Systematic Botany from the Missouri Botanical Garden 60: 242-271.

Hauman, L.L. 1921. Deux graminées géantes de la flore Argentine. Vol. 5. Physis, Buenos Aires. Pp. 52-56.

International Union for Conservation of Nature (IUCN). 2015. The IUCN red list of threatened species. Version 2014.3. Disponible en $<$ http://www. iucnredlist.org >. Acceso en 27 Octubre 2015.

Monteiro, S.H.N. 2007. Revisão taxonômica e filogenia do gênero Galeandra Lindl. (Catasetinae: Orchidaceae). Tesis Doctoral. Universidade Estadual de Feira de Santana, Feira de Santana. $178 \mathrm{p}$.

Monteiro, S.H.N.; Silva M.F.F. \& Secco, R.S. 2009. O gênero Galeandra (Orchidaceae) na Amazônia Brasileira. Acta Amazonica 39: 21-34.

Monteiro, S.H.N.; Selbach-Schnadelbach, A.; de Oliveira, R.P. \& van den Berg, C. 2010. Molecular phylogenetics of Galeandra (Orchidaceae: Catasetinae) based on plastid and nuclear DNA sequences. Systematic Botany 35: 476-486.

Schinini, A. 2008. Orchidaceae. In: Zuloaga, F.O.; Morrone, O. \& Belgrano, M.J. (eds.). Catálogo de las plantas vasculares del Cono Sur (Argentina, Sur de Brasil, Chile, Paraguay y Uruguay). Monographs 
in Systematic Botany from the Missouri Botanical Garden 107: 2712-2730.

Stearn, W.T. 2004. Botanical latin. Timber Press, Portland. 546p.

Thiers, B. [permanentemente actualizado]. Index Herbariorum: A global directory of public herbaria and associated staff. New York Botanical Garden's Virtual Herbarium. Disponible en $<$ http:// sweetgum.nybg.org/ih>. Acceso en 27 Octubre 2015.

Williams, L.O. 1939. Las Orquidáceas del Noroeste Argentino. Lilloa 4: 337-375. 